\title{
Nature's Way of Protection: Innate Resistance to Malaria
}

\section{Ernst Hempelmann*}

Center of Cellular and Molecular Biology of Diseases, Instituto de Investigaciones Científicas y Servicios de Alta Tecnología (INDICASAT AIP), City of Knowledge,

Republic of Panama

*Corresponding Author: Ernst Hempelmann, Center of Cellular and Molecular

Biology of Diseases, Instituto de Investigaciones Científicas y Servicios de Alta

Tecnología (INDICASAT AIP), City of Knowledge, Republic of Panama.
Received: May 24, 2021

Published: June 09, 2021

(C) All rights are reserved by Ernst

Hempelmann

\section{Abstract}

The malaria parasite has co-evolved with its human host. This has had a profound effect on the genetic variability in host response to malaria.

This review will focus on RBC modifications, such as sickle cell, thalassemia's, glucose-6-phosphate dehydrogenase deficiency and ovalocytosis frequent in persons living in endemic malaria settings.

Keywords: Malaria; Hemoglobin; Sickle Cell

\section{Introduction}

Innate resistance to malaria occurs through both modifications of the immune system that enhance immunity to this infection and also by changes in human red blood cells that hinder the malaria parasite's ability to invade and replicate within these cells. Host resistance to malaria therefore involves not only blood cell genes such as abnormal hemoglobins, Glucose-6-phosphate dehydrogenase deficiency, and Duffy antigens, which provide innate resistance, but also genes involved in immunity such as the major histocompatibility complex genes, which regulate adaptive immune responses [35]. Pathogen-selected red blood cell modification aids survival through the dangerous years of early childhood, while the potent protection mediated by adaptive immune responses is more important in older children and adults living where malaria is endemic.

Individuals of different genotypes vary in "fitness", the probability that their genes will be passed on to the next generation. The term includes survival through reproductive age and relative fer- tility. Under some conditions genetic diversity [polymorphism] is stable, for example when a heterozygote has a fitness greater than that of either homozygote, whereas under other conditions polymorphism is unstable. Persons homozygous for abnormal hemoglobin $[\mathrm{Hb}]$ genes often have fitness's lower than those with normal $\mathrm{Hb}$, while heterozygotes have a greater fitness because of relative resistance to malaria, thereby maintaining stable polymorphisms in malarious environments. Where this parasite is endemic young children have repeated malaria attacks. These are initially severe, and can be fatal, usually because of serious anemia or cerebral malaria. Repeated malaria infections strengthen adaptive immunity and broaden its effects against parasites expressing different surface antigens. By school age most children have developed efficacious adaptive immunity against malaria. These observations raise questions about mechanisms that favor the survival of most children in Africa while allowing some to develop potentially lethal infections. Evidence has accumulated that the first line of defense against malaria is provided by genetically controlled innate resistance, mainly exerted by abnormal hemoglobins and glucose-6-phosphate dehy- 
drogenase deficiency. However, the potent effect of genetically controlled innate resistance is reflected in the probability of survival of young children in malarious environments. It is necessary to study innate immunity in the susceptible age group, younger than four years; in older children and adults the effects of innate immunity are overshadowed by those of adaptive immunity. It is also necessary to study populations in which random use of antimalarial drugs does not occur.

\section{Glucose-6-phosphate dehydrogenase deficiency}

Glucose-6-phosphate dehydrogenase [G6PD] is an enzyme in red cells, metabolizing glucose through the pentose phosphate pathway and maintaining a reducing environment. G6PD is present in all human cells but is particularly important to red blood cells. Since mature red blood cells lack nuclei and cytoplasmic RNA, they cannot synthesize new enzyme molecules to replace genetically abnormal or ageing ones. All proteins, including enzymes, have to last for the entire lifetime of the red blood cell, which is normally 120 days. In 1956 Alving and colleagues showed that in some African Americans the antimalarial drug primaquine induces hemolytic anemia, and that those individuals have an inherited deficiency of G6PD in erythrocytes [11].

G6PD deficiency is sex linked, and common in Mediterranean, African and other populations. In Mediterranean countries such individuals can develop a hemolytic diathesis [favism] after consuming fava beans. G6PD deficient persons are also sensitive to several drugs in addition to primaquine. G6PD deficiency is the most common enzyme deficiency in humans, estimated to affect some 400 million people [14].

\section{Malaria in G6PD-deficient subjects}

This question has been studied in isolated populations where antimalarial drugs were not used in Tanzania, East Africa [7], and in the Republic of the Gambia, West Africa, following children during the period when they are most susceptible to Falciparum malaria [22]. In both cases parasite counts were significantly lower in G6PD-deficient persons than in those with normal red cell enzymes. The association has also been studied in individuals, which is possible because the enzyme deficiency is sex-linked and female heterozygotes are mosaics due to lyonization, where random inactivation of an X-chromosome in certain cells creates a population of G6PD deficient red blood cells coexisting with normal red blood cells. Malaria parasites were significantly more often observed in normal red cells than in enzyme-deficient cells [36]. An evolutionary genetic analysis of malarial selection on G6PD deficiency genes has been published by Tishkoff and Verelli [51].

\section{Sickle-cell}

The World Health Organization has estimated that at least 5\% of the world's population are carriers for one or other of the most serious forms of the haemoglobinopathies, either the disruption of the balanced synthesis of the $\alpha$ - and $\beta$-globins or the structural variant hemoglobins S, C and E [21]. Sickle cell was the first disease for which an underlying molecular cause was identified. The first report of sickle cell anaemia may have been in a report in 1846 where the autopsy report of an executed runaway slave was discussed [31]. In 1910 a Chicago physician, James B. Herrick, reported the presence of sickle cells in the blood of an anaemic dental student, Walter Clement Noel [24]. These cells had first been observed by his intern Ernest Irons while they were treating Noel in 1904. The disease was named sickle cell anaemia by Verne Mason [37] after several additional cases were reported. All the known cases had been reported in blacks and he concluded that this disease was confined to those of black African descent.

In 1927 Vernon Hahn and Elizabeth Biermann Gillespie showed that sickling of the red cells was related to low oxygen. In some individuals this change occurs at partial pressures of $\mathrm{O}_{2}$ prevalent in the body, and produces anemia and other disorders, termed sickle-cell disease. In other persons sickling occurs only at very low $\mathrm{O}_{2}$ partial pressures; these are asymptomatic sickle-cell trait carriers [23].

In 1946, E A Beet, a British medical officer stationed in Southern Rhodesia [Zimbabwe], observed that blood from malaria patients who had sickle cell trait had fewer malarial parasites than blood from patients without the trait and suggested that this might be a protective feature. In 1949 Lehmann and Raper published a map of Uganda and showed that the presence of sickle cell anaemia cor- 
related with the presence of malaria [32]. P. Brain while working in Northern Rhodesia confirmed the lower incidence of splenomegaly and suggested that while homozygotes for the sickle cell gene suffered from several problems heterozygotes might be protected against malaria [15].
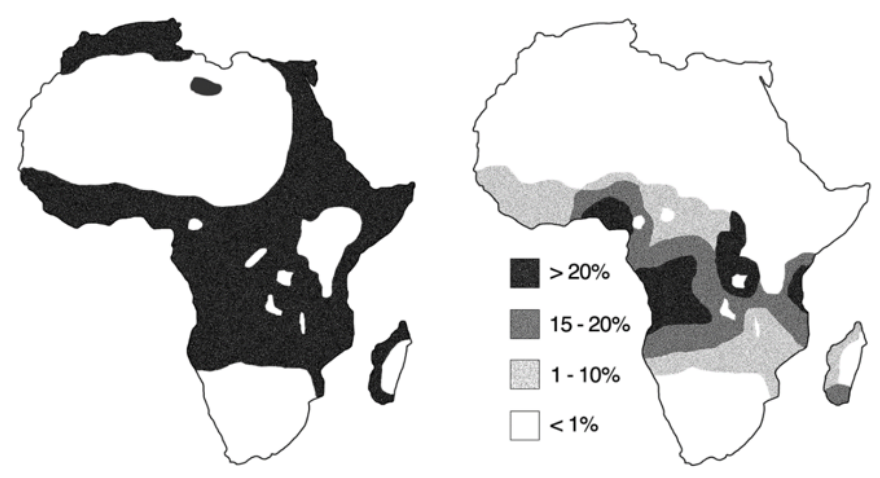

Figure 1: Left: regions in Africa where falciparum malaria was transmitted before control was introduced. Right: Frequencies of sickle-cell heterozygotes in indigenous African population

(Courtesy, Tony Allison).

Differences in electrophoretic mobilities between normal hemoglobin and that from patients with sickle cell anemia [Hb S] were seen by Pauling and his associates. The experiments were carried out in a Tiselius moving-boundary electrophoresis apparatus, the duration of the runs varied from 6 to 20 hours. Pauling's group had done electrophoresis studies on hemoglobins from 15 persons with sickle cell anemia, 8 with sicklemia [now called sickle call trait, the heterozygous condition], and 7 with normal blood. The results indicated that a significant difference exists between the electrophoretic mobilities of hemoglobin derived from erythrocytes of normal individuals and from those of sickle cell anemic individuals, one of the two components of sicklemia hemoglobin was identical with sickle cell anemia hemoglobin and the other was identical with the normal compound [45]. In sickle-cell trait carriers there is a nearly equal amount of $\mathrm{HbA}$ and $\mathrm{HbS}$, whereas in persons with sickle-cell disease nearly all the $\mathrm{Hb}$ is of the $\mathrm{S}$ type, apart from a small amount of fetal $\mathrm{Hb}$. These observations showed that most patients with sickle-cell disease are homozygous for the gene encoding HbS, while trait carriers are heterozygous for this gene. Persons inheriting a sickle-cell gene and another mutant at the same locus, e.g. a thalassemia gene, can also have a variant form of sickle-cell disease.
The next major advance was the discovery by Vernom Ingram in 1959 that HbS differs from HbA by only a single amino-acid substitution in the $\beta$-polypeptide chain [ $\beta 6 \mathrm{Glu} \rightarrow \mathrm{Val}$ ] [26]. It was later established that this results from a substitution of thymine for adenine in the DNA codon [GAG $\rightarrow$ GTG]. This was the first example in any species of the effects of a mutation on a protein.

\section{Distribution of the sickle-cell gene}

Since sickle-cell homozygotes are at a strong selective disadvantage, while protection against malaria favors the heterozygotes, it would be expected that high frequencies of the $\mathrm{HbS}$ gene would be found only in populations living in regions where malaria transmission is intense or was so until the disease was eradicated. In a second study conducted in 1953 Allison showed that this was true in East Africa [3-5]. Frequencies of sickle-cell heterozygotes were $20-40 \%$ in malarious areas, whereas they were very low or zero in the highlands of Kenya, Uganda, and Tanzania. Later studies by many investigators filled in the picture $[8,47]$. High frequencies of the $\mathrm{HbS}$ gene are confined to a broad belt across Central Africa, but excluding most of Ethiopia and the East African highlands; this corresponds closely to areas of malaria transmission. Sickle-cell heterozygote frequencies up to $20 \%$ also occur in pockets of India [33] and Greece [49] that were formerly highly malarious. Tens of thousands of individuals have been studied, and high frequencies of abnormal hemoglobins have not been found in any population that was malaria free.

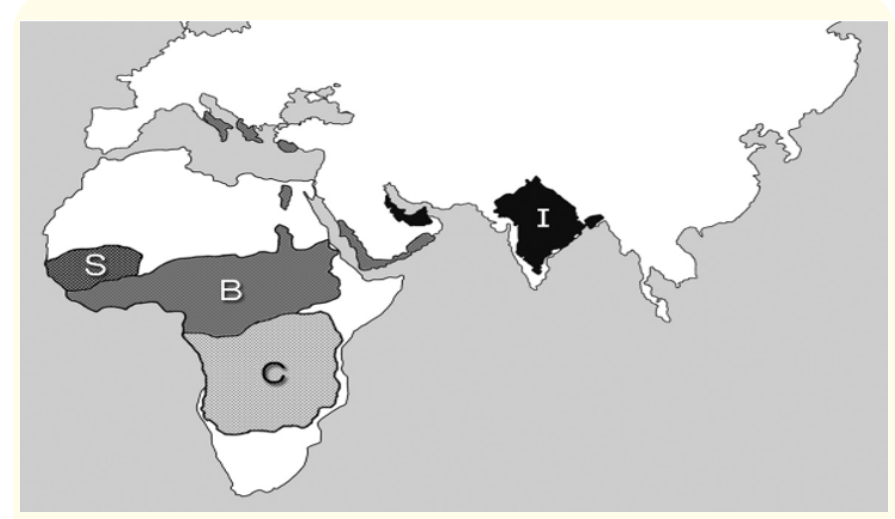

Figure 2: Independent origin of the sickle-cell gene in several locations: $\mathrm{S}=$ Senegal type; $\mathrm{B}=$ Benin type; $\mathrm{C}=$ Central African (Bantu) type; I = Indian/Arabian type (Courtesy, Tony Allison). 
Two mutations found in non-transcribed sequences of DNA adjacent to the $\beta$-globin gene are so close to each other that the likelihood of crossover is very small. Restriction endonuclease digests of the $\beta$-globin gene cluster have shown five different patterns associated with the sickle-cell [GAG $\rightarrow$ GTG] mutation. Four are observed in Africa, the Bantu, Benin, Senegal and Cameroon types [30], and a fifth type is found in the Indian subcontinent and Arabia [29]. The cited authors report that haplotype analysis in the $\beta$-globin region shows strong linkage disequilibrium over the distance indicated, which is evidence that the $\mathrm{HbS}$ mutation occurred independently at least five times. The high levels of AS in parts of Africa and India resulted from independent selections occurring in different populations living in malarious environments. In summary, the demonstration that sickle-cell heterozygotes have some degree of protection against falciparum malaria was the first example of genetically controlled innate resistance to human malaria, as recognized by experts on inherited factors affecting human infectious diseases [2]. It was also the first demonstration of Darwinian selection in humans, as recognized by evolutionary biologists [10].

\section{Thalassemias}

It has long been known that a kind of anemia, termed thalassemia, has a high frequency in some Mediterranean populations, including Greeks and Southern Italians. The name is derived from the Greek words for sea [thalassa], meaning the Mediterranean sea and blood [haima]. Vernon Ingram deserves the credit for explaining the genetic basis of different forms of thalassemia as an imbalance in the synthesis of the two polypeptide chains of $\mathrm{Hb}$ [27]. In the common Mediterranean variant, mutations decrease production of the $\beta$-chain [ $\beta$-thalassemia]. In $\alpha$-thalassemia, which is relatively frequent in Africa and several other countries, production of the $\alpha$ chain of $\mathrm{Hb}$ is impaired, and there is relative over-production of the $\beta$-chain. Individuals homozygous for $\beta$-thalassemia have severe anemia and are unlikely to survive and reproduce, so selection against the gene is strong. Those homozygous for $\alpha$ thalassemia also suffer from anemia and there is some degree of selection against the gene.

Little is known about the malaria-protective effects when HbS and thalassemia are inherited in combination. In a population studies on the coast of Kenya it was found that the protection afforded by each condition inherited alone was lost when the two conditions were inherited together.

\section{Other abnormal hemoglobins}

The frequencies of abnormal hemoglobins in different populations vary greatly, but some are undoubtedly polymorphic, having frequencies higher than expected by recurrent mutation. Four of these are $\alpha$-thalassemia, which attains frequencies of $30 \%$ in parts of West Africa [38]; $\beta$-thalassemia, with frequencies up to $10 \%$ in parts of Italy; HbE [ $\beta 26 \mathrm{Glu} \rightarrow$ Lys], which attains frequencies up to $55 \%$ in Thailand and other Southeast Asian countries [20]; and $\mathrm{HbC}$ [ $\beta 6 \mathrm{Glu} \rightarrow \mathrm{Lys}$, which attains frequencies approaching $20 \%$ in northern Ghana and Burkina-Faso. All of these are in malarious areas, and there is evidence that the persons with $\alpha$-thalassemia, $\mathrm{HbC}$ and $\mathrm{HbE}$ have some degree of protection against the parasite $[25,44]$. There is no longer doubt that malarial selection played a major role in the distribution of all these polymorphisms. An additional question is raised by the presence of polymorphisms for $\mathrm{HbS}$ and another $\mathrm{Hb}$ mutation in the sample population. Double heterozygotes for $\mathrm{HbS}$ and $\beta$-thalassemia, and for $\mathrm{HbS}$ and $\mathrm{HbC}$, suffer from variant forms of sickle-cell disease, milder than SS but likely to reduce fitness before modern treatment was available. As predicted, these variant alleles tend to be mutually exclusive in populations. There is a negative correlation between frequencies of $\mathrm{HbS}$ and $\beta$-thalassemia in different parts of Greece and of $\mathrm{HbS}$ and $\mathrm{HbC}$ in West Africa. Where there is no adverse interaction of mutations, as in the case of abnormal hemoglobins and G6PD deficiency, a positive correlation of these variant alleles in populations would be expected and is found [6].

\section{South-East Asian ovalocytosis}

Ovalocytosis is an inherited condition in which erythrocytes have an oval instead of a round shape. In most populations ovalocytosis is rare, but South-East Asian ovalocytosis [SAO] occurs in as many as $15 \%$ of the indigenous people of Malaysia and of $\mathrm{Pa}-$ pua new Guinea. Several abnormalities of SAO erythrocytes have been reported, including increased red cell rigidity and reduced expression of some red cell antigens [28]. SAO is caused by a mutation in the gene encoding the erythrocyte band 3 protein. There is a deletion of codons $400-408$ in the gene, leading to a deletion of 9 amino-acids at the boundary between the cytoplasmic and transmembrane domains of band 3 protein [35]. Band 3 serves as the principal binding site for the membrane skeleton, a submembrane protein network composed of ankyrin, spectrin, actin, and band 4.1. Ovalocyte band 3 binds more tightly than normal band 3 
to ankyrin, which connects the membrane skeleton to the band 3 anion transporter. These qualitative defects create a red blood cell membrane that is less tolerant of shear stress and more susceptible to permanent deformation.

\section{Resistance in South Asia}

The lowest Himalayan Foothills and Inner Terai or Doon Valleys of Nepal and India are highly malarial due to a warm climate and marshes sustained during the dry season by groundwater percolating down from the higher hills. Malarial forests were intentionally maintained by the rulers of Nepal as a defensive measure. Humans attempting to live in this zone suffered much higher mortality than at higher elevations or below on the drier Gangetic Plain.

However, the Tharu people had lived in this zone long enough to evolve resistance via multiple genes. Medical studies among the Tharu and non-Tharu population of the Terai yielded the evidence that the prevalence of cases of residual malaria is nearly seven times lower among Tharus. The basis for their resistance to malaria is most likely a genetic factor. Endogamy along caste and ethnic lines appear to have confined these to the Tharu community $[42,50]$. Otherwise, these genes probably would have become nearly universal in South Asia and beyond because of their considerable survival value and the apparent lack of negative effects comparable to Sickle Cell Anemia.

\section{Duffy antigen receptor}

The malaria parasite Plasmodium vivax is estimated to infect 75 million people annually. $P$. vivax has a wide distribution in tropical countries, but is absent or rare in a large region in West and Central Africa, as recently confirmed by PCR species typing [19]. This gap in distribution has been attributed to the lack of expression of the Duffy antigen receptor for chemokines [DARC] on the red cells of many sub-Saharan Africans. Duffy negative individuals are homozygous for a DARC allele, carrying a single nucleotide mutation [DARC $46 \mathrm{~T} \rightarrow \mathrm{C}$ ], which impairs promoter activity by disrupting a binding site for the hGATA1 erythroid lineage transcription factor [52]. In widely cited in vitro and in vivo studies, Miller., et al. reported that the Duffy blood group is the receptor for P. vivax and that the absence of the Duffy blood group on red cells is the resistance factor to P. vivax in persons of African descent [41]. This has become a well-known example of innate resistance to an infectious agent because of the absence of a receptor for the agent on target cells. However, observations have accumulated showing that the original report needs qualification. P. vivax can be transmitted in Squirrel monkeys [Saimiri boliviensis and S. sciureus], and Barnwell., et al. [13] have obtained evidence that P. vivax enters Saimiri monkey red cells independently of the Duffy blood group, showing that $P$. vivax has an alternative pathway for invading these cells. The Duffy binding protein, the one and only invasion ligand for DARC, does not bind to Saimiri erythrocytes although these cells express DARC and obviously become infected with $P$. vivax [53]. The question is whether these observations are relevant to naturally occurring human transmission of $P$. vivax. Ryan., et al. presented evidence for the transmission of $P$. vivax among a Duffynegative population in Western Kenya [47]. Independently, Cavasini., et al. have reported P. vivax infections in Duffy antigen-negative individuals from the Brazilian Amazon region [17]. P. vivax and Duffy antigen expression were identified by genotypic and other methods. A subsequent investigation in Madagascar has extended these observations [40]. The Malagasy people in this island have an admixture of Duffy-positive and Duffy-negative people of diverse ethnic backgrounds. At eight sentinel sites covering different parts of the island $72 \%$ of the populations were Duffy-negative, as shown by genotyping and flow cytometry. P. vivax positivity was found in $8.8 \%$ of 476 asymptomatic Duffy-negative people, and clinical P. vivax malaria was found in 17 such persons. Genotyping of polymorphic and microsatellite markers suggested that multiple $P$. vivax strains were invading the red cells of Duffy-negative people. The authors suggest that among Malagasy populations there are enough Duffy-positive people to maintain mosquito transmission and liver infection. From this internal source $P$. vivax variants can develop, using receptors other than Duffy to enter red cells and multiply. More recently, Duffy negative individuals infected with two different strains [VK247 and classic strains] of P. vivax were found in Angola and Equatorial Guinea; further, P. vivax infections were found both in humans and mosquitoes, which means that active transmission is occurring. This finding reinforces the idea that this parasite is able to use receptors other than Duffy to invade erythrocytes, which may have an enormous impact in P. vivax current distribution [40]. Because of these several reports from different parts of the world it is clear that some variants of $P$. vivax are being transmitted to humans who are not expressing DARC on their red cells. The frequency of such transmission is still unknown.

$P$. vivax is clearly a less potent agent of natural selection that is $P$. falciparum. However, the morbidity of $P$. vivax is not negligible. For example, $P$. vivax infections induce a greater inflammatory 
response in the lungs than is observed in P. falciparum infections, and progressive alveolar capillary dysfunction is observed after the treatment of vivax malaria [12]. Epidemiological studies in the Amazonian region of Brazil have shown that the number and rate of hospital admissions for P. vivax infections have recently increased while those of $P$. falciparum have decreased [48]. Standard criteria for admission were used. The authors suggest that $P$. vivax infections in this region are becoming more severe. In summary, $P$. vivax can bind to and invade human and nonhuman primate erythrocytes through a receptor or receptors other than DARC. However, DARC still appears to be a major receptor for human transmission of $P$. vivax. The potency of $P$. vivax as an agent of natural selection is unknown, and may vary from location to location. DARC negativity remains a good example of innate resistance to an infection, but it produces a relative and not an absolute resistance to $P$. vivax transmission.

\section{Natural selection}

Natural selection was traditionally attributed to phenomena such as competition for resources or predation. There was no example of natural selection operating on a common gene in humans, in contrast to selection against rare deleterious mutations. After the Second World War an Italian group [E. Silvestroni, I. Bianco and G. Montalenti] developed methods for identifying ß-thalassemia heterozygotes in populations, and recorded their frequencies in different parts of Italy. In some regions heterozygote frequencies up to $10 \%$ were observed, and the strong geographic correspondence between the incidence of thalassemia and endemic malaria was noted, as documented by an Italian historian of science [16]. At an international meeting in Italy in 1949 J.B.S. Haldane gave an address on „Disease and Evolution“. In the ensuing discussion Montalenti presented information on the distribution of thalassemia in Italy and acknowledged a suggestion from J.B.S. Haldane that thalassemic heterozygotes may be resistant to malaria [44]. Later in 1949 Haldane reiterated the same suggestion, with no reference to the Italian investigators. Haldane is therefore widely regarded as the originator of the „malaria hypothesis“. However, there have been suggestions that the role of Italian investigators in recognizing this correlation was insufficiently acknowledged [18].

\section{Testing the malaria hypothesis}

The first systematic investigation of the malaria hypothesis was conducted by Anthony Allison in East Africa in 1953. His initial study ascertained whether sickle-cell heterozygotes are protected against severe P. falciparum infections. This required working

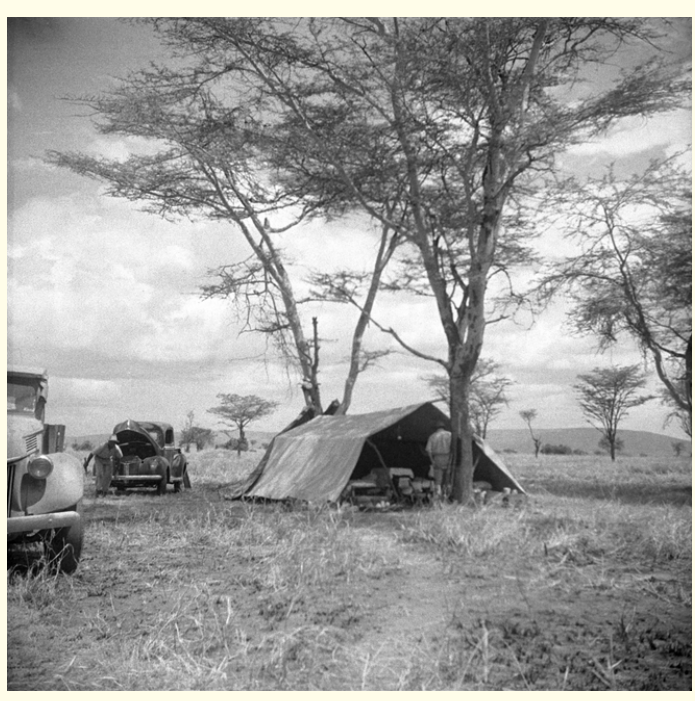

Figure 3: Tony Allison's safari to collect human blood samples and investigate the relationship between sickle-cell trait and resistance to malaria, 1953 (Courtesy, Tony Allison).

with children between four months and four years of age, when the morbidity and mortality from malaria is greatest. The study was done in Ugandan villages where antimalarial drugs were not used. Allison found that children in this age group carrying $\mathrm{HbS}$ had significantly lower malaria parasite counts than in those with $\mathrm{HbA}$ [4]. Severe morbidity and mortality in malaria were known to be correlated with high parasite counts.

This observation has been confirmed many times in different parts of Africa, and potentially lethal manifestations of malaria [cerebral malaria and severe anemia] are rare in sickle-cell heterozygotes $[6,38]$. In the latter study the $\mathrm{HbS}$ carrier state was found to be negatively associated with all potentially lethal forms of $P$. falciparum malaria, whereas the negative associations of the carrier states of $\mathrm{HbC}$ and $\alpha$-thalassemia were limited to cerebral malaria and severe anemia, respectively. These findings strongly suggest that, under conditions of intense $P$. falciparum transmission, young sickle-cell heterozygotes [AS] survive better than those with normal hemoglobin [AA], whereas sickle-cell homozygotes [SS] survive least well of all three genotypes.

Detailed study of a cohort of 1022 Kenyan children living near Lake Victoria, published in 2002, confirmed this prediction [1]. Many SS children still died before they attained one year of age. Between 2 and 16 months the mortality in AS children was found to be significantly lower than that in AA chil- 
dren. This well-controlled investigation shows the ongoing action of natural selection through disease in a human population.

\section{Conclusion}

It is estimated that malaria is responsible for 1 to 3 million deaths and 300-500 million infections annually. The ever-evolving malaria drug resistant, international travel, and climatic changes poses a major problem for the developing countries. Today almost all strains of Plasmodium falciparum parasites are resistant to Chloroquine one of the best anti-malarial. A better understanding of host red blood cell variants may uncover new strategies for the development of novel antimalarial therapeutics.

\section{Bibliography}

1. Aidoo M., et al. "Protective effects of the sickle cell gene against malaria morbidity and mortality". Lancet 359.9314 (2002): 1311-1312.

2. Alcaïs A., et al. "Human genetics of infectious diseases: between proof of principle and paradigm". Journal of Clinical Investigation 119.9 (2009): 2505-2514.

3. Allison AC. "Notes on sickle-cell polymorphism". Annals of Human Genetics 19 (1954a): 39-57.

4. Allison AC. "The distribution of the sickle-cell trait in East Africa and elsewhere, and its apparent relationship to the incidence of subtertian malaria". Transactions of the Royal Society of Tropical Medicine and Hygiene 48.4 (1954b): 312-318.

5. Allison AC. "Protection Afforded by Sickle-cell Trait Against Subtertian Malaria Infection”. British Medical Journal 1.4857 (1954c): 290-294.

6. Allison AC. "Aspects of polymorphism in man". Cold Spring Harbor Symposia on Quantitative Biology 20 (1955): 239-251.

7. Allison AC and Clyde DF. "Malaria in African Children with Deficient Erythrocyte Glucose-6-phosphate Dehydrogenase". British Medical Journal 1.5236 (1961): 1346-1349.

8. Allison AC. "The discovery of resistance to malaria of sicklecell heterozygotes". Biochemistry and Molecular Biology Education 30 (2002): 279-287.

9. Allison AC. "Genetic control of resistance to human malaria". Current Opinion in Immunology 21.5 (2009a): 499-505.
10. Allison AC. "A sickle-cell safari, chapter 8". in: Sean B Carroll Into the Jungle: Great adventures in the search for evolution, San Francisco, Pearson Benjamin Cummings (2009b): 148165.

11. Alving AS., et al. "Enzymatic deficiency in primaquine-sensitive erythrocytes". Science 124.3220 (1956): 484-485.

12. Anstey NM., et al. "Lung Injury in Vivax Malaria: Pathophysiological Evidence for Pulmonary Vascular Sequestration and Posttreatment Alveolar-Capillary Inflammation". Journal of Infectious Diseases 195.4 (2007): 589-596.

13. Barnwell JW., et al. "In vitro evaluation of the role of the Duffy blood group in erythrocyte invasion by Plasmodium vivax". Journal of Experimental Medicine 169.5 (1989): 1795-1802.

14. Beutler E. "Glucose-6-phosphate dehydrogenase deficiency: a historical perspective". Blood 111.1 (2008): 16-24.

15. Brain P. "Sickle-cell Anaemia in Africa". British Medical Journal 2 (1952): 880.

16. Canali S. "Researches on thalassemia and malaria in Italy and the origins of the "Haldane hypothesis". Medicina nei Secoli 20.3 (2008): 827-846.

17. Cavasini CE., et al. "Duffy the Brazilian Amazon region". Malaria Journal 6.1 (2007): 167.

18. Ceppellini R. "Discussion of "Aspects of Polymorphism in Man". Cold Spring Harbor Symposia on Quantitative Biology 20 (1955): 251-255.

19. Culleton RL., et al. "Failure to detect Plasmodium vivax in West and Central Africa by PCR species typing". Malaria Journal 7.1 (2008): 174.

20. Flatz G. "Hemoglobin E: distribution and population dynamics”. Humangenetik 3.3 (1967): 189-234.

21. Flint J., et al. "The population gentics of the haemoglobinopathies”. Balliere's Clinical Haematology 6 (1993): 215-262.

22. Guindo A., et al. "X-linked G6PD deficiency protects hemizygous males but not heterozygous females against severe malaria". PLoS Medicine 4.3 (2007): e66.

23. Hahn EV and Gillespie EB. "Sickle cell anemia. Report of a case greatly improved by splenectomy. Experimental study of sickle cell formation". Archives of Internal Medicine 39.2 (1927): 233-254. 
24. Herrick JB. "Peculiar elongated and sickle-shaped red blood corpuscles in a case of severe anemia". Archives of Internal Medicine 5 (1910): 517-521. Reprinted in Herrick JB (2001) Peculiar elongated and sickle-shaped red blood corpuscules in a case of severe anemis 1910. Yale J Biol Med 74.3 (1910): 179-184.

25. Hutagalung R., et al. "Influence of hemoglobin E trait on the severity of Falciparum malaria”. Journal of Infectious Diseases 179.1 (1999): 283-286.

26. Ingram VM. "Abnormal human haemoglobins. III. The chemical difference between normal and sickle cell haemoglobins". Biochimica et Biophysica Acta 36.2 (1959a): 402-411.

27. Ingram VM and Stretton AO. "Genetic basis of the thalassaemia diseases”. Nature 184.4703 (1959b): 1903-1909.

28. Jarolim P., et al. "Deletion in erythrocyte band 3 gene in malaria-resistant Southeast Asian ovalocytosis". Proceedings of the National Academy of Sciences of the United States of America 88.24 (1991): 11022-11026.

29. Labie D., et al. "Haplotypes in tribal Indians bearing the sicklegene: evidence for the unicentric origin of the BS mutation and the unicentric origin of tribal populaton in India". Human Biology 61.4 (1989): 479-491.

30. Lapouméroulie C., et al. "A novel sickle cell mutation of yet another origin in Africa: the Cameroon type". Human Genetics 89.3 (1992): 333-337.

31. Lebby R. "Case of absence of the spleen". Southern Medical Journal 1 (1846): 481-483.

32. Lehmann $\mathrm{H}$ and Raper AB. "Distribution of sickle cell trait in Uganda, and its ethnological significance". Nature 164.4168 (1949): 494-495.

33. Lehmann $\mathrm{H}$ and Cutbush M. "Sickle cell trait in southern India”. British Medical Journal 6 (1952): 404-405.

34. Liu SC., et al. "Molecular defect of the band 3 protein in southeast Asian ovalocytosis". The New England Journal of Medicine 323.22 (1990): 1530-1538.

35. López C., et al. "Mechanisms of genetically-based resistance to malaria". Gene 467.1-2 (2010): 1-12.
36. Luzzatto L., et al. "Glucose-6-phosphate dehydrogenase deficient red cells: Resistance of infection by malaria parasites". Science 164 (1969): 839-841.

37. Mason VR. "Sickle cell anemia”. JAMA 79 (1922): 1318-1320.

38. May J., et al. "Hemoglobin variants and disease manifestations in severe falciparum malaria". JAMA 297.20 (2007): 22202226.

39. Ménard D., et al. "Plasmodium vivax clinical malaria is commonly observed in Duffy-negative Malagasy people". Proceedings of the National Academy of Sciences of the United States of America 107.13 (2010): 5967-5971.

40. Mendes C., et al. "Duffy negative antigen is no longer a barrier to Plasmodium vivax - molecular evidences from the African West Coast (Angola and Equatorial Guinea)". PLOS Neglected Tropical Diseases 5.6 (2011): e1192.

41. Miller LH., et al. "The resistance factor to Plasmodium vivax in blacks. The Duffy-blood-group genotype, FyFy". The New England Journal of Medicine 295.6 (1976): 302-304.

42. Modiano G., et al. "Protection against malaria morbidity: nearfixation of alpha-thalassemia gene in a Nepalese population". American Journal of Human Genetics 48 (1991): 390-397.

43. Modiano D., et al. "Haemoglobin C protects against clinical Plasmodium faciparum malaria”. Nature 414.6861 (2001): 305-308.

44. Montalenti G. "Comment on Haldane, JBS. Disease and evolution”. Rice Science 19 (1949): 333-334.

45. Pauling L., et al. "Sickle cell anemia, a molecular disease". Science 110.2865 (1949): 543-548.

46. Piel FB., et al. "Global distribution of the sickle gene and geographical confirmation of the malaria hypothesis". Nature Communication 104.8 (2010): 1-7.

47. Ryan JR., et al. "Evidence for transmission of Plasmodium vivax among a duffy antigen negative population in Western Kenia". American Society of Tropical Medicine and Hygiene 75.4 (2006): 575-581.

48. Santos-Ciminera PD., et al. "Malaria Diagnosis and Hospitalization Trends, Brazil". Emerging Infectious Diseases 13.10 (2007): 1597-1600. 
49. Stamatoyannopoulos G and Fessas P. "Thalassemia, glucose6-phosphate dehydrogenase deficiency, sickling and malarial endemicity in Greece. A study of five areas". British Medical Journal 1.5387 (1964): 875-879.

50. Terrenato L., et al. "Decreased malaria morbidity in the Tharu people compared to sympatric populations in Nepal". Annals of Tropical Medicine and Parasitology 82.1 (1988): 1-11.

51. Tournamille C., et al. "Disruption of a GATA motif in the Duffy gene promotor abolishes erythroid gene expression in Duffynegative individuals". Nature Genetics 10.2 (1995) 224-228.

52. Wertheimer SP and Barnwell JW. "Plasmodium vivax interaction with the human Duffy blood group glycoprotein: identification of a parasite receptor-like protein". Experimental Parasitology 69.4 (1989): 340-350.

53. WHO. World Malaria Report 2014, World Health Organization, 20 Avenue Appia, CH-1211 Geneva 27, Switzerland (2014).

54. Williams TN., et al. "Negative epistasis between the malariaprotective effects of alpha+-thalassemia and the sickle cell trait". Nature Genetics 37 (2005): 1253-1257.

Volume 5 Issue 7 July 2021

(c) All rights are reserved by Ernst Hempelmann. 